\title{
Interação dialógica: Uma proposta teórico-metodológica em ambientes virtuais de aprendizagem
}

\section{Dialogic interaction: A theoretic-methodological proposal in virtual learning environments}

\author{
Prof. ${ }^{a}$ Dr. ${ }^{a}$ Margarete Axt* \\ Prof. ${ }^{a}$ Dr. ${ }^{a}$ Carime Rossi Elias** \\ Dnd. ${ }^{a}$ Janete Sander Costa***

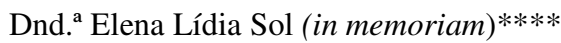 \\ Grnd. ${ }^{a}$ Paloma Dias Silveira*****
}

Resumo: Este texto pretende contribuir para a discussão teórico-metodológica no âmbito da educação a distância, a partir do relato de uma experimentação realizada em Curso de Especialização, na Universidade Federal do Rio Grande do Sul (UFRGS), em disciplina aqui denominada pela sigla $A C$ - $A V A$. O objetivo é colocar em análise a relação de interdependência produzida entre ambiente telemático de aprendizagem, características da ferramenta utilizada e concepção teórica que sustenta a prática pedagógica. Acredita-se que a telemática, assim como outras modalidades tecnológicas, não tem valor em si, mas depende das propostas de trabalho em que se insere. E, reciprocamente, o desenvolvimento de uma proposta teórico-metodológica precisa pensar a sua prática embutida no suporte tecnológico no qual se inscreve.

Palavras-chave: Interação dialógica. Proposta teórico-metodológica. Autoria coletiva. Ambientes virtuais de aprendizagem. Educação a Distância.

Abstract: This study intends to contribute to a theoretic-methodological discussion in the distance education scope. It is based on a report about an experimentation that took place in a Specialization Course at the Federal University of Rio Grande do Sul (UFRGS) during the hereby designated as $A C$ - $A V A$ course. It aims at placing into analysis the interdependence relation produced between a virtual learning environment, the characteristics of the utilized software and the theoretical conception that sustains the pedagogical practice. It is believed that 'telematics', as other technological modalities, do not have value in itself, but depends on the work proposal in which it is inserted. Reciprocally, the development of a certain theoretic-methodological proposal shall think its practice to be inbuilt in the technological support in which it is employed.

Keywords: Dialogic-interaction. Theoretic-methodological proposal. Collective authorship. Virtual learning environments. Distance Learning.

\footnotetext{
* Docente nos Programas PPGIE/UFRGS e PPGEDU/UFRGS, coordenadora do Laboratório de Estudos em Linguagem, Interação e Cognição, LELIC/UFRGS, pesquisadora do CNPq. maaxt@ufrgs.br

**Pesquisadora do LELIC, professora da UERGS e consultora de projetos da UAPPG da UNISINOS. carime@terra.com.br

***Pesquisadora do LELIC, doutoranda do PPGIE/UFRGS. Professora afastada da UCS-CAMVA. janetesander@gmail.com

****Pesquisadora do LELIC, doutoranda do PPGEDU/UFRGS, de março de 2003 a junho de 2006.

*****Pesquisadora do LELIC, graduanda da Pedagogia/UFRGS. palomadsil@hotmail.com 


\section{Introdução}

Este texto pretende contribuir para a discussão teórico-metodológica no âmbito da educação a distância (EAD), a partir do relato de uma experimentação realizada em Curso de Especialização, na Universidade Federal do Rio Grande do Sul (UFRGS), em disciplina que denominaremos pela sigla $A C-A V A^{\mathrm{i}}$. O objetivo é colocar em análise a relação de interdependência que se produz entre ambiente telemático de aprendizagem, características da ferramenta utilizada e concepção teórica, que sustenta a prática pedagógica, podendo-se incluir aí modos de avaliação ${ }^{\mathrm{ii}}$. Acredita-se que a telemática, assim como outras modalidades tecnológicas, não tem valor em si, mas depende das propostas de trabalho em que se insere. E, reciprocamente, o desenvolvimento de uma proposta teórico-metodológica não pode deixar de pensar sua prática articulada ao suporte tecnológico no qual se inscreve.

\section{A proposta metodológica: histórico}

A proposta metodológica, de natureza interacional-dialógica, adotada na disciplina $A C-A V A$ do curso de especialização, já vem sendo desenvolvida há algum tempo, desde 1996. Encontra-se em processo de desenvolvimento e consolidação, sofrendo adaptações, conforme o nível ou a modalidade de ensino considerada (pósgraduação, graduação, extensão) ou as características do suporte tecnológico utilizado na interação a distância (lista de discussão, plataforma/ambiente de aprendizagem, ferramenta de comunicação).

Em 1996 e 1999, essa proposta metodológica foi gestada para o desenvolvimento de disciplinas na pós-graduação stricto sensu, com o suporte de listas de discussão, sendo que a versão de 1996 previa reuniões presenciais no início e ao final da disciplina, enquanto que a de 1999 contemplava reuniões presenciais quinzenais ${ }^{\text {iii }}$.

Em 1998, desenvolveu-se uma versão da disciplina para curso de aperfeiçoamento (formação continuada para professores em serviço), totalmente a distância, em plataforma/ambiente de aprendizagem ${ }^{\text {iv }}$, cuja principal ferramenta para interação a distância era o fórum. Já aqui entrava em cena uma equipe formadora, com voluntários da pós-graduação stricto sensu.

Em 2001, com reedição em 2002, a proposta metodológica inscreveu-se novamente na pós-graduação stricto sensu, agora em fase de consolidação, sustentada pela plataforma $A V E N C C A$ cuja principal ferramenta é o forchat ${ }^{\mathrm{v}}$. As reuniões presenciais seguiam a rotina quinzenal, enquanto os encontros virtuais eram tanto síncronos quanto assíncronos. Nessas duas versões, além dos monitores bolsistas que davam o suporte técnico à disciplina, os próprios alunos-participantes contribuíam na sustentação do grupo, sendo que na segunda versão parte dos alunos encontrava-se totalmente a distância, sem participação nas reuniões presenciais. Acompanhavam as disciplinas, listas de discussão para resolução de problemas operacionais ${ }^{\mathrm{vi}}$.

No biênio 2001-2002, a proposta foi testada na graduação, no curso de pedagogia, com o mesmo suporte tecnológico, agora agregando uma equipe de formadores voluntários (alunos da pós-graduação PPGEDU/PPGIE), interessados em tornar este espaço de docência, campo empírico para pesquisa ${ }^{\text {vii }}$. Os encontros presenciais eram semanais, seguidos de interação síncrona no ambiente virtual, sendo que todas as alunas se encontravam no mesmo laboratório. As contribuições assíncronas foram raras.

Essa experiência de interação dialógica também foi levada a efeito no curso de especialização, em pauta no presente artigo, aí adquirindo nova conotação, uma vez que 
precisava se adequar a outro suporte tecnológico, o TelEduc ${ }^{\text {viii }}$, plataforma oficial do curso, bem como inscrever-se numa estrutura padrão do próprio curso. Era de interesse, nesse contexto, considerar como foco (já referido), para análise, justamente uma relação de interdependência que pretensamente se cria entre teoria/prática e suporte tecnológico.

\section{Metodologia: $A C-A V A$ no curso de especialização}

A estrutura do curso de especialização em pauta prevê, para todas as disciplinas, encontros presenciais na primeira e última semana do semestre letivo. No período restante - entre essas duas semanas inicial e final -, o curso prevê encontros a distância semanais síncronos: para cada disciplina, um dia da semana e um horário específicos, quando então o grupo de alunos participantes mantém contato com os colegas e a equipe formadora para discussão de conteúdos e esclarecimento de dúvidas.

Com relação à disciplina $A C$ - $A V A$ do curso de especialização, objeto de reflexão do presente artigo, pôde-se considerar de início que o planejamento foi realizado coletivamente pela equipe de formadoras ${ }^{\mathrm{x}}$ : o grupo de alunos teria encontros síncronos de uma hora, às segundas-feiras, e o objetivo seria a discussão teórica de textos previamente determinados mediante cronograma; a leitura dos textos indicados seria obrigatória e anterior aos encontros síncronos.

Os conteúdos da bibliografia estavam relacionados à temática da autoria (coletiva), de modo que, considerando o contexto de interação dialógica possibilitado ao coletivo na disciplina, uma questão-desafio, deveria atravessar todas as discussões do grupo: como se produz e se vivencia uma situação de autoria coletiva na rede virtual, e como se pode referenciar esta situação nos autores em estudo?! A implantação do plano de estudo realizou-se conforme o previsto, ao longo do semestre: participaram da disciplina 28 alunos, sendo que houve uma desistência (do curso).

A plataforma-ambiente TelEduc foi utilizada para os encontros síncronos e também para as discussões assíncronas. O ambiente virtual de apoio à aprendizagem, utilizado pelos professores do curso, oferece ferramentas de interação, como: sala de bate-papo (chat), para os encontros síncronos; fórum, para os comentários teóricos registrados no decorrer da semana, tanto pelos alunos, como pelas formadoras; correio, para as mensagens mais imediatas e gerais; e portfólio, onde os alunos registravam os trabalhos da disciplina ${ }^{\mathrm{x}}$. Interessa-nos, neste texto, em relação às ferramentas disponíveis no Teleduc, discutir em especial os espaços de interlocução abertos pelo chat e pelo fórum, embora também tenhamos utilizado o correio e o portfólio.

O TelEduc possui outras ferramentas possíveis de serem utilizadas. No entanto, a opção pela utilização específica desses espaços, na $A C$ - $A V A$, se deu em função da proposta de trabalho, de caráter interacional, em virtude do número de alunos participantes. No entendimento da equipe, um número elevado de espaços de participação tenderia a dispersar o grupo (também grande), não facilitando as discussões coletivas (ao contrário, diminuindo a intensidade das interações) e dificultando o trabalho de acompanhamento, pelas formadoras, dos movimentos interacionaisdialógicos dos participantes.

Além do ambiente TelEduc, onde ocorreu a maior parte das interações, também houve experimentações com a ferramenta-ambiente, Equitext ${ }^{\mathrm{xi}}$, que possibilita a construção colaborativa de textos na Web. Para essa tarefa, a turma foi dividida em cinco grupos, que postavam diferentes registros, a partir de uma proposta inicial feita pela equipe, de tentar construir um texto coletivo, ficcional, e não de caráter conceitual, como nas ferramentas do ambiente Teleduc. A construção de narrativas coletivas não visou ao controle das histórias que seriam construídas, mas ao exercício de construir coletivamente. Para tanto, foi solicitado a cada aluno, já na primeira aula presencial, que 
criasse seu próprio personagem, e, a partir da interação com os personagens dos colegas participantes da narrativa coletiva, a história fosse sendo produzida ${ }^{\text {xii }}$. Interessante observar que os autores também poderiam deixar vazia a pele de seus próprios personagens, adentrando a pele de personagens criados por seus colegas, o que acabava por emprestar ao personagem um caráter de total imprevisibilidade, como já notado em Axt et al. (2002) $)^{\text {xiii }}$. Também o EquiText, assim como o TelEduc, apresenta, ainda, outros espaços de registro menos interativos que não foram explorados pela $A C-A V A$, tendo em vista a proposta em pauta.

Em síntese, a proposta metodológica privilegia espaços que favorecem alto grau de interação, em virtude da perspectiva conversacional-dialógica adotada, de modo que aqueles espaços, seja no TelEduc ou no EquiText, que mais se conformavam a esta exigência, foram mais e melhor explorados.

Nesse sentido, dobra-se o suporte tecnológico a serviço de uma proposta metodológica. E, reciprocamente, adaptam-se, a proposta e a prática pedagógica, à realidade disponibilizada pelo suporte tecnológico, evitando-se que percam sua especificidade interacional-dialógica.

É como marca dessa proposta, que estamos chamando de interacional-dialógica, que ainda outro aspecto característico se coloca em evidência: o da produção de condições de ressonância dialógica (ou de respondibilidade/responsabilidade ${ }^{\text {xiv }}$ ) entre diferentes dimensões/planos que se constituem no interior desses espaços virtuais de interação. Em suma, é sempre, ao mesmo tempo, que na $A C$ - $A V A$ :

- $\quad$ escrevemos/registramos, e também discutimos o conceito de autoria;

- escrevemos imersos nas relações de cooperação e reciprocidade, e também discutimos o conceito de autoria coletiva;

- $\quad$ lemos, como leitores ativos que somos, as mensagens de nossos colegas e as nossas próprias, e também problematizamos o conceito de leitor;

- interagimos conversacionalmente a partir dos registros escritos, em diferentes momentos e também discutimos os conceitos de dialogismo e texto; ambientes vivenciamos a necessidade de participação do outro (para que os pudessem funcionar), e também discutimos os complexos conceitos de respondibilidade e responsabilidade.

Bakhtin supõe que cada um de nós 'não tem álibi na existência'. Nós próprios precisamos ser responsáveis ou respondíveis por nós mesmos. Cada um de nós ocupa um lugar e um tempo únicos na existência, uma existência que é concebida não como um estado passivo, mas ativamente, como um acontecimento. (CLARK e HOLQUIST, 1998, p.90)

Ainda, outros conceitos como o de 'silêncio', não previstos como objeto de discussão no planejamento da disciplina, acabaram por ser abordados porque emergiram nas discussões dos alunos como referência ao que estavam vivenciando.

\section{Metodologia: referencial teórico}

A opção pelo ambiente telemático, pelas ferramentas e pela quantidade de espaços a serem povoados, foi orientada pela capacidade técnica, que ambiente e ferramentas tinham de possibilitar à participação coletiva, interação dialógica entre os 
participantes, e também pela viabilidade de acompanhamento pela equipe dos registros publicados pelos alunos.

As variações entre os tipos de ferramentas permitiram que vivenciássemos (alunos e equipe) diferentes modalidades de participação no coletivo; não somente porque as próprias ferramentas, do ponto de vista da usabilidade técnica, diferenciavamse entre si, mas também porque as propostas de construção coletiva foram diferenciadas. No EquiText, o desafio era a construção de uma narrativa ficcional coletiva, onde o que importava não era o resultado, mas a vivência no grupo, o encontro com o registro inesperado, a experiência de descentramento e estranhamento em relação ao registro do outro, bem como em relação ao próprio texto sempre em processo de transformação pelas novas contribuições, e em relação a si mesmo, enquanto simultaneamente autor e personagem, e autor e leitor.

Já no Teleduc, na sala de bate-papo (espaço síncrono de discussões semanais, em horário previamente definido), a experiência coletiva tinha como objetivo, na discussão conceitual, uma troca de conhecimentos forjada principalmente no embate e na partilha de interpretações diferentes a partir da leitura de textos comuns: literalmente, o espaço de linguagem como "arena" de lutas entre significações (BAKHTIN, 2002, p. 46).

No espaço do Teleduc/Fórum, um outro tipo de coletivo foi vivenciado. Ainda que fundamentalmente conceitual, como o bate-papo, o tempo de registros e de respostas no Fórum era assíncrono, produzindo a possibilidade de maior reflexividade e elaboração das questões conceituais ao longo da semana, bem como sua postagem em qualquer momento a partir de duas orientações: discussão do texto lido, naquela semana, ou a retomada de questões abordadas no bate-papo e, neste caso, com a referência explícita ao autor/participante do grupo. O Fórum, a cada semana, ou a cada nova leitura, recebia um novo espaço temático de discussão referido à leitura em pauta. Por exemplo, quando, por ocasião da interação que exercitava a construção ficcional no EquiText, os alunos, ao mesmo tempo liam o texto "Era uma vez..." (AXT ET AL., 2002) e o discutiam, assincronamente, no Fórum homônimo.

Ainda que sob modalidades diferenciadas, em cada um desses espaços de interação havia como que uma consigna implícita: escrevia-se para o outro, fosse o outro um colega de grupo, ou o outro constituído pela equipe de formadoras, ou ainda o outro discursivo dos enunciados dos autores lidos. O coletivo movia o ambiente. Era a partir do outro que nós nos sentíamos convocados, ou não, a participar. A partir do coletivo, o próprio espaço (de aprendizagem, de autoria) ia sendo produzido.

Neste sentido, a possibilidade de produção coletiva responde a dois pressupostos teóricos: (a) do diálogo como constitutivo do movimento do aprender; e (b) da aprendizagem como processo autoral, ao mesmo tempo individual e coletivo. Tais pressupostos orientaram, tanto as escolhas das ferramentas a serem utilizadas (chat, fórum e escrita colaborativa no EquiText), quanto a metodologia de trabalho e as opções pelos modos avaliativos, ou seja, a proposta teórico-metodológica vivenciada.

No caso do Fórum, à medida que as discussões evoluíam a partir de um texto previamente informado, cada aluno se engajava, ora em uma discussão conceitual, ora em outra. Deste modo, em um mesmo momento, e com respeito a um mesmo tema, um participante produzia um trajeto interlocutivo, que percorria conceitos como os de leitor, autor e texto, enquanto outro poderia estar construindo um caminho que fosse da leitura, à respondibilidade e ao silêncio, por exemplo. Esse modo de participação permite que cada um vá construindo o seu próprio percurso de discussão ao longo da disciplina e é esse caminho que será objeto de reconstrução no seu trabalho final ${ }^{\mathrm{xv}}$.

Aqui, encontra-se a concepção de autoria, na perspectiva da possibilidade de expressão, interligada à concepção de aprendizagem como processo, ao mesmo V. $4 \mathrm{~N}^{\mathrm{o}} 1$, Julho, 2006 
tempo individual e coletivo à medida que cada participante, enquanto produz o seu próprio percurso interlocutivo, o faz inscrito no interior de um coletivo; e dentro de um campo definido pela temática da disciplina e pelas abordagens dos textos previamente definidos $^{\mathrm{xvi}}$.

\section{Metodologia: à guisa de conclusão}

O quadro teórico-metodológico da disciplina $A C$ - $A V A$ remete preponderantemente a Mikhail Bakhtin e ao seu conceito de dialogismo. Então, ao mesmo tempo em que é discutido conceitualmente, o próprio referencial em discussão serve como dispositivo para a proposição de se vivenciar, no âmbito da disciplina, a linguagem como materialidade, considerando o dialogismo como o princípio constitutivo da possibilidade de interação. Não se trata, então, de apenas falar-se sobre, mas de se viver com, exercitando na coexistência dos diversos modos de interagir, a alteridade na linguagem.

Braith (1997) reforça a idéia de alteridade, que se inscreve no dialogismo de Bakhtin, trazendo duas acepções que se interpenetram: uma dimensão do diálogo entre interlocutores, à medida que todo enunciado está sempre orientado para alguém, que, por sua vez, é um ouvinte, e, nesse caso, um leitor ativo, que responde mesmo que com o silêncio; e a acepção do diálogo entre discursos, enquanto tecido de muitas vozes. Aqui, autor e leitor não são vistos como a origem de seu próprio dizer, antes, se trata do plano dos discursos, das conexões que os próprios enunciados discursivos estabelecem uns com os outros, percorrendo uma temporalidade não cronológica; formas típicas de enunciados (ou gêneros de discurso) organizam nossa fala, sugere Bakhtin (2000, p. 301). Para o autor, cada enunciado é um elo da cadeia muito complexa de outros enunciados (p.291): compõem um enunciado, tanto as ressonâncias dialógicas que remetem aos enunciados anteriores do outro discursivo (p. 326), quanto, ao mesmo tempo, as marcas (sempre tênues) da alternância entre interlocutores concretos, que sulcam cada enunciado por dentro, a expressão de um se infiltrando e se difundindo no discurso do outro.

Segundo esses movimentos de um diálogo orientado ao outro, (ao mesmo tempo em planos vivenciais discursivos diferentes, de ficção e de reflexão conceitual) e, simultaneamente, de conexão entre os enunciados formulados nesses diferentes espaços/planos de interlocução, se poderia dizer que a metodologia de trabalho na disciplina configurou-se na interdependência entre: (i) as diferentes vivências coletivas virtuais (telemáticas), (ii) o quadro teórico-conceitual trabalhado e (iii) a prática pedagógica explorada, de natureza interacional-dialógica. Ao mesmo tempo em que se vivenciavam experiências coletivas diferentes (fossem no campo da exercitação ficcional, fossem no da interlocução/discussão conceitual), essas vivências eram discutidas do ponto de vista conceitual a partir principalmente do referencial bakhtiniano de dialogismo, além de alguns outros autores como Eco (1997), Orlandi (1988) e Axt (2004).

Em outras palavras, institui-se, para além dos movimentos dialógicos voltados à alteridade, um outro movimento complexo também de duas dimensões, as quais se produzem mutuamente: (a) a dimensão dos sentidos produzidos na exercitação vivencial, nos diferentes espaços interlocutivos do TelEduc e do EquiText, constituindo matéria para o pensamento compreensivo conceitual; e (b) a das significações produzidas na reflexão conceitual, que se voltam aos espaços de interlocução na disciplina, dobrando-se conforme as particularidades de cada espaço, ressoando sobre os processos de produção de sentido que, em cada um dos participantes, se engendra diferenciadamente. 
Esse movimento complexo, cujas dimensões se dobram uma sobre a outra, acaba por definir a singularidade de cada espaço tecnológico enquanto ele próprio dobra-se com a metodologia interacional-dialógica: assim, é no espaço-TelEduc-fórum que se expressa um pensamento compreensivo conceitual mais elaborado e com especificidades individuais mais marcadas. ${ }^{x i i}$ É no espaço-TelEduc-chat que a interlocução sofre aceleração adquirindo conotação fortemente vivencial, coletiva. E é no espaço-EquiText que a produção coletiva, levada pelos fluxos cotidianos dos próprios personagens, tende a perder seus caracteres (ilusoriamente) individuais - o que inclusive se expressa por resistências na participação. ${ }^{\text {xiii }}$

Deste modo, é por acreditar que as tecnologias para a aprendizagem dependem, grande parte, das propostas de trabalho em que se inscrevem que se buscou apresentar uma experimentação em que ambiente telemático de aprendizagem, tipos de ferramentas e metodologia de trabalho configurassem uma rede de relações tecida a partir de opções teóricas. Assim, conceitos como dialogismo, autoria e aprendizagem como processo, centrais na proposta de trabalho, permitiram a experimentação de processos coletivos de interação dialógica, que dependiam de cada participação/registro individual em movimentos de autoria. Ao mesmo tempo, os diferentes percursos produzindo o coletivo constituíram diferentes movimentos de aprendizagem em cada um dos participantes.

\section{NOTAS}

i O Curso de Especialização define sua ênfase no campo da Informática na Educação (ESPIE) e vem sendo oferecido regularmente pelo Centro Interdisciplinar de Novas Tecnologias na Educação (CINTED/UFRGS), estando já em sua $3^{\mathrm{a}}$ edição.

ii Observa-se que a avaliação não constitui aspecto de interesse no presente texto.

iii Análises e discussão de resultados da edição de 1999, em AXT E ELIAS (2003). Disciplinas realizadas no PPGEDU/UFRGS.

iv Plataforma PROINFO/SEED/MEC, desenvolvida com a assessoria do Laboratório de Estudos Cognitivos (LEC/PSI/UFRGS), este último sendo responsável, também, pela coordenação do curso.

v A plataforma AVENCCA e a ferramenta de comunicação a distância forchat foram desenvolvidas no LELIC/UFRGS, sob a coordenação da Prof. ${ }^{a}$ Dr. ${ }^{a}$ Margarete Axt.

vi Análises e discussões de resultados têm sido gerados, desde então, por vários dos participantes dessas duas edições da disciplina (realizadas no PPGEDU e no PPGIE), na forma de artigos, dissertações de mestrado e tese de doutorado. Assim, trabalhos referindo experiências com esta proposta metodológica têm produzido artigos como AXT Et Al. (2003a) e COSTA, AXT, TAROUCO, MEHLECKE (2005); dissertações de mestrado como as de SOUZA, E. Tecnologias digitais na escola pública: Possibilidade de exercício de autoria na formação de professores, MOREIRA, G. Tecnologias da Informação e Comunicação na escola pública: sentidos produzidos na formação continuada de professores, do PPGEDU/MEAD; LEDUR, R., Produção de sentido na arte contemporânea, do PPGEDU, as três defendidas em 2005, sob orientação da Dra. Margarete Axt; e de NOVAK, S. O problema da interação na era da 
aprendizagem autônoma: pressupostos epistemológicos da educação a distância na perspectiva construtivista. 2005. 294 f. (Orientador: Prof. Dr. Sérgio Franco); teses de doutorado, como a de MEHLECKE, Q., Relações Dialógicas no ambiente de suporte à aprendizagem on-line: um estudo das estratégias no contexto de falantes da língua portuguesa de Portugal, do PPGIE/UFRGS, 2006, sob orientação da Prof. ${ }^{\text {a }}$ Dr. ${ }^{a}$ Liane Tarouco e co-orientação da Prof. ${ }^{a}$ Dr. $^{a}$ Margarete Axt. Outros trabalhos, artigos, dissertações de mestrado e teses de doutorado se encontram em andamento, no PPGEDU e PPGIE, sob orientação da Prof. ${ }^{a}$ Dr. ${ }^{a}$ Margarete Axt, seguem esta proposta teórico-metodoloógica.

vii Análises e discussão de resultados em AXT ET AL. (2003b) e em AXT E KREUTZ (2003). Além dessa publicação, participantes da experiência compondo a equipe de formadores voluntários produziram teses de doutorado como ELIAS, C. R. (Des)caminhos do aprender: uma perspectiva teórico-metodológica que busca aproximar aprendizagem e sentido/acontecimento, Programa de Pós-Graduação em Educação da UFRGS, 2003; MATTE, MARLENI NASCIMENTO. Autoria no ambiente virtual pedagógico. 2005. 206 f. (Orientadora: Prof. ${ }^{a}$ Dr. ${ }^{a}$ Regina Mutti). Em forma de artigo: COSTA, J.S.; MEHLECKE, Q.; REICHERT, C.L. (2005), REICHERT, C. L; COSTA, J. S.; FRANCISCO, D. J.; MACHADO, G. J. C.; BIANCAMANO, M. R. (2004), dentre outros.

viii TeleEduc, ambiente de ensino a distância pelo qual se pode realizar cursos através da Internet. Está sendo desenvolvido conjuntamente pelo Núcleo de Informática Aplicada à Educação (NIEd) e pelo Instituto de Computação (IC), da Universidade Estadual de Campinas (UNICAMP), e disponibilizado gratuitamente para fins educacionais: <http://teleduc332.cinted.ufrgs.br/ teleduc/pagina_inicial/index.php?>. Acesso em: 04/jul./2006.

ix A equipe de formadoras da disciplina em questão foi composta pela professora titular, duas professoras colaboradoras, uma professora convidada e uma monitora, da Pedagogia. Esta equipe, vinculada aos PPGEDU e PPGIE, atua paralelamente no Laboratório de Estudos em Linguagem, Interação e Cognição - LELIC/UFRGS.

x O portfólio será objeto de um estudo específico, pois é central para o nosso modo de avaliação. No presente texto, correio e portfolio não serão focalizados, uma vez que fogem aos propósitos do mesmo.

xi O EquiText, ferramenta de Groupware, de escrita colaborativa na Web, criada em 1999, no PPGIE, durante a disciplina "Laboratório de Teleducação", por um grupo de alunos e bolsistas, sob orientação da Prof. ${ }^{a}$ Dr. ${ }^{a}$ Liane Tarouco, cf. Seixas (2000).

xii Também houve tentativa de utilização da ferramenta cooperativa forchat, nos primeiros encontros com o grupo de estudantes. Todavia, por impossibilidades de ordem técnica, ela não seguiu sendo utilizada.

xiii Observe-se que este, como outros aspectos provocados pela proposta interacionaldialógica, podem ser amplamente explorados numa dimensão ético-criativa/inventiva dos processos formativos.

xiv Conceitos utilizados por Bakhtin em uma série de textos e que Clark e Holquist (1998) compilam sob o título "A Arquitetônica da Respondibilidade". 
xv Esse modo de trabalho e de interação não é foco do presente texto, não sendo, portanto abordado.

xvi Como já mencionado, alguns textos não indicados previamente acabaram por ser incluídos como leitura ao longo do semestre, tendo em vista a emergência, nas discussões dos alunos, de temas não previstos, mas pertinentes à temática geral abordada.

xvii Para Bakhtin (2002), a compreensão constitui-se sempre pela inserção da palavra/texto em um novo contexto. Portanto, envolve, para além da decodificação, também a interpretação.

xviii Neste último caso, o espaço chamado "histórico", no EquiText, pode recuperar a noção de indivíduo.

\section{Referências Bibliográficas}

AXT, M.; ELIAS, C. R. Autoria coletiva, ambientes virtuais e formação: quando a aprendizagem reverbera o acontecimento. In: Cleci Maraschin; Lia B. L. Freitas; Diana C. de Carvalho. Psicologia e Educação; multiversos sentidos, olhares e experiências. P. Alegre: UFRGS, 2003.

AXT, M.; KREUTZ, J.R. Sala de aula em rede: de quando a autoria se (des)dobra em in(ter)venção. In: Tania M. G. Fonseca; Patricia G. Kirst. Cartografias e Devires; a construção do presente. P. Alegre: UFRGS, 2003.

AXT, M. et al. (2003a). Tecnologias digitais na Educação: tendências. Educar em Revista, UFPR, 2003:237-64 (número especial).

AXT, M. et al. (2003b). Rede de desassossegos: problematizações acerca de uma experiência pedagógica no ensino superior na intersecção com ambientes virtuais. Contrapontos, UNIVALE, v.3(2), mai/ago 2003: 243-54.

AXT, Margarete. A escola frente às tecnologias - pensando a concepção ético-política. In: SCHOLZE, Lia; MORAES, Salete Campos (orgs.). Caderno temático: multimeios e informática educativa. Porto Alegre: SMED/POA, 2002.

AXT, Margarete. Comunidades virtuais de aprendizagem. Informática na Educação: teoria \& prática, Porto Alegre, v.7, n.1, jan./jun. 2004. ISSN 1516-084 X. p. 111-116.

et al. Era uma vez... Uma narrativa em co-autoria no espaço virtual - co-autoria em narrativas coletivas interseccionadas por tecnologias digitais. XI Simpósio de Informática em Educação, 2001, Vitória, Espírito Santo. Anais, p.136-144, 2002.

BAKHTIN, M. O problema do texto. In: BAKHTIN, M. Estética da Criação Verbal. São Paulo: Martins Fontes, 2000.

BAKHTIN, M. (VOLOCHINOV). Marxismo e Filosofia da Linguagem. São Paulo: Hucitec, 2002. 
BRAITH, Beth (org). Bakhtin, dialogismo e construção do sentido. São Paulo: Editora Unicamp, 1997.

CLARK, K.; HOLQUIST, M. Cap.3: Arquitetônica da Respondibilidade. In: Mikhail Bakhtin. S. Paulo: Perspectiva, 1998.

COSTA, J.S.; AXT, M.; TAROUCO, L.; MEHLECKE, Q. Oral traces in written L1 and L2 interactions: Affective gifts of informal language styles in virtual learning communities. Renote, Porto Alegre, v.3, n.2, nov. 2005. Disponível em: $<$ http://www.cinted.ufrgs.br/renote> .

Acesso em 04 jul 2006.

COSTA, J.S.; MEHLECKE, Q.; REICHERT, C.L. Movimentos da oralidade nas interações escritas em um ambiente virtual de aprendizagem: novos efeitos de sentido e autoria. Anais. $12^{\circ}$ Congresso Internacional de EAD, ABED, maio 2005.

ECO, Umberto. Entre autor e texto. In: ECO, Umberto. Interpretação e superinterpretação. São Paulo: Martins Fontes, 1997.

MEHLECKE, Q.; COSTA, J. S.; AXT, M.; TAROUCO, L. Produção de sentido e autoria em curso de qualificação de professores na construção de projetos interdisciplinares de aprendizagem mediados pelo computador. Renote, Porto Alegre, v.3, n.2, nov. 2005. Disponível em: <http://www.cinted.ufrgs.br/renote> . Acesso em 04 jul 2006.

MEHLECKE, Q.; TAROUCO, L.; AXT, M.; PEREIRA, A.; COSTA, J. Estratégia de interação on-line: um estudo no contexto de falantes da língua portuguesa de Portugal. Renote, Porto Alegre v. 4, n.1 (a ser publicado em julho de 2006). Disponível em: $<$ http://www.cinted.ufrgs.br/renote $>$.

ORLANDI, E. A polissemia na noção de leitura. Discurso e Leitura. São Paulo: Unicamp e Cortez, 1998.

REICHERT, C. L; COSTA, J. S.; FRANCISCO, D. J.; MACHADO, G. J. C.; BIANCAMANO, M. R. FORCHAT: Ambiente Virtual de aprendizagem. Anais. $11^{\circ}$ Congresso Internacional de Educação a Distância, ABED, set. 2004.

REICHERT, C. L. E COSTA, J.S. Metodologia dos Desafios: Problematização e sentido em ambientes virtuais de aprendizagem. Renote, Porto Alegre, v.3, n.1, maio 2005. Disponível em: <http://www.cinted.ufrgs.br/renote> . Acesso em 04 jul 2006.

SEIXAS, Louise. Avaliação de ambientes colaborativos textuais em rede. Anais. Ribie, Chile, 2000. Disponível em: $<$ http://www.c5.cl/ieinvestiga/actas/ribie2000/papers/285/index.html $>$. Acesso em: 04/jul./2006. 